IOS Press

\title{
Obituary
}

\section{IN MEMORIAM — OGUZ K. BASKURT}

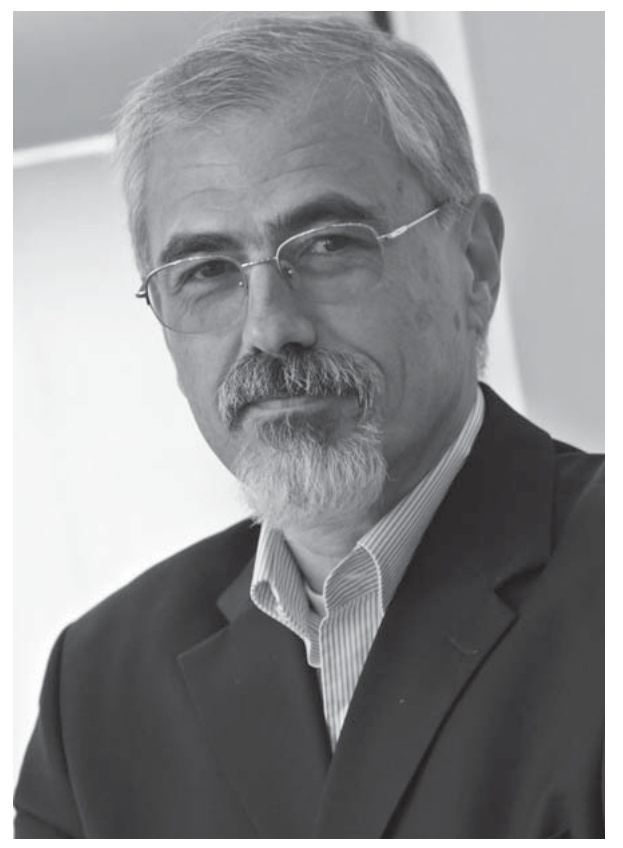

Oguz K. Baskurt, MD, PhD, Professor of Physiology, Koc University, Istanbul has died. He suffered a cerebral hemorrhage on July 13, 2013 and died one week later without regaining consciousness. There were no signs or symptoms to suggest this event and he was his usual active and friendly self at a conference in Pecs, Hungary, just prior to his acute illness. He was 57 years old.

Dr. Baskurt obtained his MD degree from Hacettepe University, Ankara, in 1982 and his PhD degree in physiology from the same university in 1988. Interestingly, his $\mathrm{PhD}$ thesis was entitled "Microrheological and Macrorheological Effects of Reticulocytosis", thus indicating an early interest in the fields of biorheology and clinical hemorheology. He was an Associate Professor at Hacettepe University, then in 1997 accepted a position as Professor of Physiology at Akdeniz University, Antalya. He moved to Koc University, Istanbul, in 2010 where he was a Professor of Physiology at the time of his death.

His contributions to the fields of biorheology and clinical hemorheology were numerous and multifaceted: a) 125 publications in peer review journals indexed by the Science Citation Index (SCI) plus 
37 other articles and 10 letters to the editor; b) over 130 invited presentations at international scientific meetings; c) two books edited and authored dealing with hemorheology (Handbook of Hemorheology and Hemodynamics and Red Blood Cell Aggregation); d) two extremely successful joint conferences of the International Society for Biorheology and the International Society for Clinical Hemorheology...one in Antalya and one in Istanbul; e) several workshops of experts dealing with topics such as the fundamentals of red blood cell (RBC) aggregation, methods for measuring this aggregation, and methods to measure RBC deformability. He was active in many national and international scientific societies and served as an elected official for several. He was scheduled to become co-Editor in Chief of the journal Biorheology with Dr. Herbert Lipowsky.

Given his large number of publications, it is impossible to capture the essence and the importance of his scientific work in few sentences. One main theme was exploring the in vivo relevance of blood rheology, RBC aggregation and RBC mechanics, with the studies dealing with renal hemodynamics, RBC distribution through the myocardium, and pressure-flow relations in isolated tissues or organs. Another was the effects of nitric oxide (NO). He was the first to show that $\mathrm{NO}$ was generated and exported by RBC exposed to shear stress and that this NO could affect vascular tone as well as RBC deformability. He explored the evolutionary aspects of comparative blood rheology including bowhead whales, echidnas, horses, kangaroos, koalas, and Tasmanian devils. Hemorheological instrument design and function were also of interest including the development of a low cost, rapid method to assess RBC aggregation. His studies were carefully done with great attention to detail and were greatly appreciated and respected by colleagues.

Dr. Baskurt was an excellent teacher and mentor. He loved to describe the scientific basis of physiology to medical and graduate students, often challenging them to think beyond the limits of a specific lecture. And, using basic concepts, they usually were successful. He was particularly interested in training graduate students and was the mentor for four MS and five PhD students. Academic training under him was both rigorous and supportive. Projects completed and published prior to starting the $\mathrm{PhD}$ work were of very high quality as were the final theses.

He was a kind, gentle and polite person who rarely raised his voice in anger, and then usually at other Turkish car drivers. However, he was willing to offer critical comments and to disagree with speakers at meetings or in private conversations. And if he was sure of his position he would not change his mind just to please anyone. He believed that a good appearance was part of a good lecture or scientific presentation and usually wore the academic "uniform" of a dark jacket, grey pants, and a blue or blue-white striped shirt with a tie. Occasionally, in very hot weather, the jacket would be removed, but probably not the tie. Nevertheless, even without the jacket and tie, he looked and acted like a distinguished Professor.

His untimely death has been a great loss to me. Oguz and I were friends and scientific colleagues for over 20 years. I first met him when he invited me to a meeting in Antalya just a few months prior to the Gulf War. We discovered areas of mutual interest that resulted in a Fulbright scholarship to join me in 1995. Surprisingly, we rapidly became friends in spite of our differences: he was calm and polite while I tended to joke and be very informal - he often wore a tie while I didn't own one that was presentable. This friendship grew and lead to several reciprocal visits to our labs, hospitality in our homes during such visits, and occasional periods of vacation exploring Turkey with our wives. We were in almost daily contact via email and had weekly telephone conversations. We published 82 peer-review papers together as well as co-editing and co-writing two books. Oguz was always ready for new aspects of bio- and hemorheology, and so we visited Australia to study blood from several animal species and to the most northern part of Alaska (City of Barrow) to investigate the rheology of bowhead whale blood. I really miss him. 
The world has lost a wonderful man and a superb scientist, physiologist and teacher. His death has saddened his many international friends and caused all of us to respect life and live it in its fullest. While he is no longer with us, his memory and his outstanding scientific achievements live on. All of his friends and scientific colleagues wish him peace and extend our condolences to his family.

Herbert J. Meiselman, ScD

Los Angeles, CA, USA

August, 2013 